\title{
Knowledge and Attitude of Family Member of Mentally Ill Patient regarding Restraint, 2016
}

\section{Shrestha $Y^{*}$}

JF Institute of Health Sciences, Hattiban, Lalitpur, Nepal

*Corresponding author: Yashu Shrestha, JF Institute of Health Sciences, Hattiban, Lalitpur, Nepal, Tel: +9779849412269; Email: shres_yas@yahoo.com

\section{Research Article}

Volume 2 Issue 3

Received Date: April 12, 2018

Published Date: May 02, 2018

\section{Abstract}

Background: People who have observed or are aware that a consumer has been restrained may experience distress, confusion, concern, anger or fear and perceive as punishment. However, studies that examine the perspective of patient's family are limited. This study has explored the knowledge and attitude of family member of mentally ill patient.

Method: A descriptive cross-sectional study was carried out among family member of mentally ill patient at Punarjeevan Hospital, Balkumari, Lalitpur to assess the knowledge and attitude of family member of mentally ill patient regarding restraint. Interview schedule was used to collect data related to knowledge and attitude regarding restraint along with demographic features.

Result: The average score of knowledge regarding physical restraint was 30.66 (72.99\%) and average attitude score was 4.17 (83.31\%). In the study $40 \%$ relationship was found between knowledge and attitude. Regarding the association between knowledge and selected socio-demographic variables, knowledge was found to be associated with age, educational level and relation with patient of respondents. In terms of association between attitude and selected sociodemographic variables, attitude was found to be associated with relation with patient of respondents.

Conclusion: This study concludes that family member has relevant knowledge regarding physical restraint but the knowledge regarding risk and consequences of physical restraint was lacking. In terms of attitudes about physical restraint over all attitude was found to be positive among family members but attitude regarding feeling of patient towards physical restraint was contrast.

Keywords: Attitude; Family members; Knowledge; Mentally ill patient; Restraint

\section{Introduction}

Physical restraint of people experiencing mental health problems is a coercive and traumatic procedure which is only legally permitted if it is proportionate to the risk presented [1]. 


\section{Nursing \& Healthcare International Journal}

People who have observed or are aware that a consumer has been restrained or secluded may experience distress, confusion, concern, anger or fear. They may also believe that the intervention was used as a punishment. It is important to address the concerns of other consumers and anyone else who observed the incident (such as visitors, students, and non-mental health staff on the unit). It is also necessary to provide reassurance that the aim is to maintain the overall safety of consumers, staff and visitors to the unit [2].

Physical restraint is always used as last resort of treatment when other method fails to prevent patient from harming self and other but when needed, it should not be delayed. It is used in violent, aggressive and selfdestructive behavior mostly [3].

Although the law requires the use of least restrictive interventions to manage psychotic or suicidal clients, the use of restrains, may be necessary to immobilize agitated, self-destructive clients [4].

There should always be one person present near patients who are violent, aggressive and self-destructive and are kept in physical restraint when patient is meeting his/her basic needs. Providing information to family member about careful observation of the patient help prevent these behavior. Explaining nature of symptoms of violence, aggressiveness, excitement and self-destructive behavior to family member it helps to recognize the early symptoms and prevent before the harmful behavior [3].

The health care personnel should always offer support to the family member. Families may be confused, angry or embarrassed when the client is restrained. Detail explanatory of client's behavior and use of physical restraint, duration and risk that can arise should be done to the family because explanation can reduce or prevent negative perception and attitude. Also providing information increase knowledge about physical restraint and it helps prevent risk arising from physical restraint [5].

Consideration should be given to the level of hydration, nutritional needs, skin integrity, circulation, hygiene, need to eliminate and any signs of physical discomfort or emotional distress, anticipating the person's need for fluids, food, and mouth care or bathing [2].

\section{Methods}

A descriptive cross sectional study was conducted at Punarjeevan Hospital, Lalitpur, Nepal. During 10 days duration of data collection interview schedule were used by the researcher herself to collect data from 90 family member of mentally ill patient attending psychiatric OPD as a convenience purposive sampling for 10-15 minutes for each interview. Consent was obtained from the participants and numbers were used instead of their names during interview schedule to maintain confidentiality. The researcher gave self-introduction and explained objectives of the study, took consent and collected data without hampering their other activities.

An interview schedule was design to assess demographic data of participants, their educational level and relation with patient, knowledge regarding restraint and attitude regarding restraint.

\section{Data Analysis Procedure}

The data obtained was analyzed on the basis of the objectives of the study using descriptive statistics and inferential statistics. After collection of data from interview schedule, the data was edited, organized, coded (For knowledge, if the answer was correct it scored 1 and if incorrect it scored 0 . For attitude, the score was given accordingly) and entered into Statistical Package for Social Sciences (SPSS version 20) and prepared for analysis.

Frequency and percentage was used for distribution of demographic variables and frequency, percentage, mean and standard deviation was used to determine knowledge and attitude of family member. Karl Pearson's correlation analysis was used to calculate the relationship between knowledge and attitude.

Assumptions were set and the association was assessed using ANOVA Test at 95\% confidence level between dependent and independent variables.

\section{Results}

The average mean age of patient is $38.31 \pm 15.20$ years and the age group with maximum number of respondent i.e. 35 is less than 30 years. Among total patient 53.3\% were male and $46.7 \%$ were female among which patient diagnosed with schizophrenia, schizotypal and delusional F20-F29 were 11.1\%, with mood (affective) disorder F30F39 41.2\% and neurotic, stress-related and somatoform disorder F40-F48 32.2\%. Among patient who attended OPD $47(52.2 \%)$ patient were diagnosed for 3 or more year but 40 patient had been receiving treatment for 3 and more years which implies that respondents and 
patient are unable to distinguish psychiatric and physical and physiological symptoms which is also supported by the 32 number of patient seeking treatment for less than 6 months but patient diagnosed with illness less than 6 month are only 13 patients (Tables $1 \& 2$ ).

The average age of respondent is $37.98 \pm 11.57$ years and among total respondents 33 (36.7\%) were of age group 31-40 years. Among total respondents 58.9\% were male and $41.1 \%$ were female. Among $85.6 \%$ literate respondents $44.1 \%$ has completed university level. Among the respondents visiting psychiatric OPD all responded were family members and were first-degree relatives.

Knowledge and Attitude of Respondents' regarding Physical Restraint

\begin{tabular}{|l|c|c|c|c|c|}
\hline \multicolumn{2}{|c|}{} & Mean & SD & Minimum & Maximum \\
\hline \multirow{2}{*}{ Knowledge Score } & 30.66 & 4.43 & 18 & 42 \\
\cline { 3 - 6 } & $-72.99 \%$ & $-10.53 \%$ & $-42.86 \%$ & $-100 \%$ \\
\hline \multirow{2}{*}{ Attitude Score } & 4.17 & 0.28 & 3.25 & \multicolumn{2}{c|}{4.75} \\
\cline { 2 - 6 } & $-83.31 \%$ & $-5.54 \%$ & $-65 \%$ & $-95 \%$ \\
\hline
\end{tabular}

Table 1: Show that the average knowledge of respondents of family member of mentally ill patient was 30.66 (72.9\%). The average attitude of the respondents of family member of mentally ill patient was 4.17 (83.3\%).

\begin{tabular}{|l|c|c|}
\hline \multicolumn{2}{|c|}{ Karl Pearson's Correlation } & Attitude Score \\
\hline \multirow{2}{*}{ Knowledge Score } & Sig. (2-tailed) & $.400^{* *}$ \\
\cline { 2 - 3 } & ${ }^{* *}$ Correlation is significant at the 0.01 level (2-tailed). & 0 \\
\hline \multicolumn{2}{|c|}{} \\
\hline
\end{tabular}

Table 2: Correlation between Knowledge and Attitude regarding Physical Restraint.

In regarding the correlation between knowledge and attitude regarding physical restraint in family member of mentally ill patient there was $40 \%$ relationship between knowledge and attitude of family member which is a positive moderate relationship between knowledge and attitude.

Regarding the association between knowledge and attitude regarding restraint and respondents' age, educational status and relation with patient and patients' diagnosis, duration of illness and treatment knowledge is associated with respondents' age, educational status and relation with patient and attitude is associated with relation with patient.

\section{Discussion}

In the current study family member said physical restraint is tying patient with rope by $31.1 \%$, confinement of a person in a hazard-free room by $4.4 \%$. Restraining is done by using belt by $26.7 \%$ and using bed rails by $10 \%$.Family member said postural asphyxia and strangulation are risk of physical restraint by $20 \%$ and $6.7 \%$ respectively and skin injuries and broken bones by $97.8 \%$ and $56.6 \%$ respectively. Family members also said patient become aggressive by $64.4 \%$ and they feel humiliated by $16.7 \%$. These findings are supported by a study conducted in Japan [6] where family member said physical restraint is tying a person $50.2 \%$ and locking a person in a room $45.4 \%$. Restraining is performed by using belt $24 \%$ and using side rails $31.1 \%$, risk of physical restraint includes suffocation $43.7 \%$ and muscle weakness and pressure ulcer $72.3 \%$ and patient become more aggressive and feel humiliated in $69.5 \%$.

Regarding the attitude of family members, they demonstrated all in all significantly more positive attitude towards physical restraint i.e. $4.17 \pm 0.28$. In regarding the association between age of respondent and attitude there was not statistically significant association between age and attitude ( $\mathrm{p}$-value $>0.05$ ). This result is supported by the study conducted in German where relatives demonstrated significantly more positive attitudes towards physical restraint use i.e. $3.40 \pm 0.60$ and relative's attitudes were not related to age with all groups having significantly positive attitude without any significant difference [7].

In this current study there is significant association between attitude and relation with patient as all family member were first-degree relatives at significant $\mathrm{p}$-value $<0.05$. There is a contrast in result probably due to difference in relation with patient such as first degree, 


\section{Nursing \& Healthcare International Journal}

grand-children, nieces, cousins and friends in a study conducted in German [7].

In this study only $5(5.60 \%)$ respondents said restraining should be done to all mentally ill patients which is supported by a study conducted in Patan Hospital, in which the mean score in regarding the statement all mentally ill patient should be chained and locked up is 3.58 and standard deviation 0.86 which is because of the same scenario, setting and sample [8].

\section{Conclusions}

This study concludes that family member has significant knowledge regarding physical restraint but the knowledge regarding risk and consequences of physical restraint was lacking. Regarding the knowledge related to purpose of physical restraint though majority of informants said restraining is done to patients who are violent and aggressive only some believe that their behavior actually stabilizes after restraining. In terms of attitudes about physical restraint over all attitude was found to be positive among family members but attitude regarding feeling of patient towards physical restraint was contrast.

Findings of the overall knowledge reveals that respondents have knowledge regarding physical restraint but there is need of clarification on certain areas such as risk, consequences of restraint and authorized person to order for physical restraint in hospital setting.

The result of this research can be used to analyze whether there was a need to give teaching on physical restrain to family members of patient or not. Also the data would be a guide to health personnel on psychiatric area to analyze whether family members should have knowledge about other thing related to patient care. An improvement in attitude towards physical restraint among public would lead to better practices, early identification of risk and initiation of action towards it and improvement in care rate.

\section{Acknowledgements}

I am grateful to Prof. Radha Rannabhat, Madam Sochana Sapkota, Madam Monica Bhattachan and Dr. Sudarshan Narsingh Pradhan for supporting and facilitating the study. In addition, I want to thank all the family members for participating in the study.

\section{References}

1. Perkins E, Prosser H, Riley D, Whittington R (2012) Physical restraint in a therapeutic setting; a necessary evil? Int J Law Psychiatry 35(1): 43-49.

2. American Psychiatric Nursing Association (2014) APNA Position Statement on the Use of Seclusion and Physical restraint.

3. Sudebi D (2012) Mental Health and Psychiatric Nursing $2^{\text {nd }}(E d n)$, Dillibazar, Kathmandu: Makalu Publication.

4. Shives LR (2009) Basic concepts of PsychiatricMental Health Nursing $7^{\text {th }}$ (Edn.), New Delhi: Wolters Kluwer (India) Private Limited.

5. Sharma C, Choulagai PS (2015) Essentials of Psychiatric and Mental Health Nursing ${ }^{\text {st }}(E d n$.$) ,$ Kathmandu, Nepal: Saurav and Awish.

6. Kurata S, Ojima T (2014) Knowledge, perceptions, and experiences of family caregivers and home care providers of physical restraint use with homedwelling elders: a cross-sectional study in Japan. BMC Geriatr 14: 39.

7. Haut A, Kolbe N, Strupeit S, Mayer H, Meyer G (2010) Attitudes of Relatives of Nursing Home Residents Toward Physical restraints, J Nurs Scholarsh 42(4): 448-456.

8. Rai P (2002) Knowledge, Belief and Attitude towards Mental Illness among Family members of Mentally ill patient. 